\title{
Vertical profile of the clear-sky aerosol direct radiative effect in an Alpine valley, by the synergy of ground-based measurements and radiative transfer simulations
}

\author{
Gabriele Fasano ${ }^{1,2}$ (D) Henri Diémoz ${ }^{2}$. Ilias Fountoulakis ${ }^{2} \cdot$ Claudio Cassardo $^{3}$. \\ Rei Kudo ${ }^{4}$. Anna Maria Siani ${ }^{1} \cdot$ Luca Ferrero $^{5}$
}

Received: 3 May 2021 / Accepted: 30 August 2021 / Published online: 12 October 2021

(C) The Author(s) 2021

\begin{abstract}
Atmospheric aerosols play an important role in Earth's radiative balance, directly interacting with solar radiation or influencing cloud formation and properties. In order to assess their radiative impact, it is necessary to accurately characterise their optical properties, together with their spatial and vertical distribution. The information on aerosol vertical profile is often scarce, in particular in mountainous, complex terrains. This study presents the first attempt to evaluate the shortwave aerosol direct radiative effect in the Aosta Valley, a mountainous region in the Northwestern Italian Alps. Ground-based, remote sensing instruments (a sky radiometer and an Automated Lidar Ceilometer) are used to derive two descriptions of the aerosol properties and vertical distribution: a first, more accurate description, which includes the whole spectral information about the aerosol extinction coefficient, phase function and single scattering albedo; a second, more approximate one, which only relies on spectrally constant values of aerosol single scattering albedo and asymmetry factor. This information is used as input for radiative transfer simulations, which allow to estimate, in cloudless conditions, the shortwave aerosol direct radiative effect and the vertical profile of the instantaneous heating rates in the lower layers of the atmosphere. The simulations obtained with the two descriptions do not differ significantly: they highlight a strong surface dimming (between -25 and $-50 \mathrm{~W} \mathrm{~m}^{-2}$ ) due to the presence of aerosol, with a considerable radiative absorption inside the atmospheric column (around $+30 \mathrm{~W} \mathrm{~m}^{-2}$ ), and an overall small cooling effect for the Earth-atmospheric system. The absorption of solar radiation within the atmospheric column due to aerosol leads to instantaneous heating rates up to $1.5 \mathrm{~K} \mathrm{day}^{-1}$ in the tropospheric layers below $6 \mathrm{~km}$ a.s.l. These results show that, in some conditions, the shortwave aerosol direct radiative effect can be considerable even in this Alpine environment, usually considered as relatively pristine (yearly average $\mathrm{PM}_{10}$ concentration about $20 \mu \mathrm{g} \mathrm{m}^{-3}$ ).
\end{abstract}

This article belongs to the Topical Collection: $3 r d$ AISAM National Conference

Gabriele Fasano

gabriele95.fasano@gmail.com

Extended author information available on the last page of the article. 
Keywords Atmospheric aerosol · Ground-based instruments ·

Aerosol direct radiative effect $\cdot$ Remote sensing

\section{Introduction}

Atmospheric aerosols are a minor component of Earth's atmosphere, but they have various and remarkable effects on many processes taking place in it. For example, they can dramatically degrade the air quality, thus representing a serious threat for the health of millions of people worldwide (Fuzzi et al. 2017). Atmospheric aerosols also play an important role in Earth's radiative balance, affecting it in two different ways: (a) directly, by absorbing or scattering the incoming solar radiation; (b) indirectly, by acting as Cloud Condensation Nuclei (CCN) or Ice Nuclei (IN), thereby influencing cloud formation and their radiative properties. Even though great effort has been recently made to investigate the role of aerosol in Earth's energy balance, this contribution is still subject to considerable uncertainty (Boucher et al. 2013). This hampers, for example, an accurate determination of the impact of anthropogenic aerosol on climate change. This large uncertainty is due to multiple causes: the complexity and interconnection of the physical phenomena relating aerosol, clouds and solar/terrestrial radiation; the highly irregular distribution of aerosols in the atmosphere, both in time and space, due to heterogeneity of sources and shorter lifetime compared to, e.g., greenhouse gases; the sensitivity of the aerosol radiative effect to particle optical properties. The last ones are a consequence of the aerosol microphysical properties, which in turn depend on aerosol origin and composition. It is vital, then, to accurately characterise and describe the aerosol microphysical properties and distribution.

The aerosol properties and distribution have been analysed with different techniques, such as remote sensing from satellite and surface instruments or in situ observations. Beside other methods, the sunphotometric technique has been successfully applied in recent years (Dubovik et al. 2000; Nakajima et al. 2020; Sinyuk et al. 2020) to retrieve accurate estimates of aerosol column-integrated properties, such as aerosol optical depth (AOD), single scattering albedo (SSA), refractive index, particle scattering phase function and volume size distribution. This methodology relies on modern sun/sky radiometers that are able to measure direct sun irradiances and diffuse sky radiances at different wavelengths. From these quantities it is possible to retrieve the aerosol columnar properties using suitable inversion algorithms.

While these methods allow to accurately quantify the aerosol amount and properties along the atmospheric column, it is also highly important to take the particle vertical distribution into account. Indeed, this can influence the profile of the aerosol radiative effects and has potential consequences on atmospheric stability, especially in the Planetary Boundary Layer (PBL, Barbaro et al. (2014), Kudo et al. (2018), and Su et al. (2020)). Surface energy fluxes, surface temperature and PBL height can be altered depending on aerosol abundance, absorption/scattering properties and vertical structure in the lower atmosphere. The information along the vertical coordinate is even more important in areas characterised by complex orography, such as mountain environments and Alpine basin valleys, where the specific morphological and meteorological conditions pose additional challenges to the study of aerosol dispersion (Ferrero et al. 2014; Diémoz et al. 2019). Unfortunately, obtaining this kind of information is often difficult, and requires particular instruments or techniques; therefore, detailed knowledge about the aerosol vertical distribution is often limited to short, intensive campaigns (Ferrero et al. 2018). As a result, vertical information about aerosol properties and distribution is scarcely available, especially in mountainous regions. 
There is another reason that makes information about the aerosol vertical distribution in a mountainous area particularly relevant: the aerosol vertical profile and its radiative effect are considered among the possible drivers for the Elevation-Dependent Warming (EDW) (Pepin et al. 2015; Thornton et al. 2021). The latter is the enhanced warming currently being observed in high-altitude regions of the world with respect to the climate change observed at lower altitudes. This is a topic of great interest in the current climatic research, because of its possible impacts on fragile ecosystems and water availability.

The aerosol direct radiative effect has been assessed in other studies, using various techniques. Trends in the aerosol direct radiative effect at a global scale have been investigated, for example by means of satellite data and radiative transfer simulations (e.g. Subba et al. 2020). In this latter study, a significant decreasing trend (i.e. reduced cooling effect) was found during the 2001-2017 period globally, but with large geographical inhomogeneities. These trends can be primarily attributed to anthropogenic aerosols. Direct radiative effect and atmospheric heating rates (HR) due to aerosols have been quantified in different areas using ground-based measurements, coupled with aerosol modeling and radiative transfer simulations (Kedia et al. 2010; Srivastava et al. 2012; Meloni et al. 2015). Coming closer to the site of our study, black carbon profiles have been investigated over three basin valleys in Italy (Ferrero et al. 2014), by collecting experimental data with the use of tethered balloons. Aerosol direct radiative effect and atmospheric heating rates were then estimated with a radiative transfer model.

The present work took place in the Aosta Valley, a mountainous region in the Northwestern Italian Alps. The study aimed at investigating quantitatively, for cloudless conditions, the shortwave aerosol direct radiative effect in an Alpine environment, using the most accurate information on aerosol optical properties and vertical distribution available on site. It is worth noting that this is the very first attempt to conduct a similar investigation in this region of the Alps. In order to obtain such information, ground-based measurements from a state-of-the-art sky radiometer were inverted using a recently developed inversion algorithm, here employed for one of the first times (Kudo et al. 2021), to retrieve accurate, spectral aerosol optical properties. The aerosol vertical distribution in the atmosphere above the valley was obtained with an Automated Lidar Ceilometer. Then, radiative transfer simulations were performed to calculate, under different conditions, the direct radiative effect and atmospheric heating rate due to aerosols.

This paper is structured as follows: Section 2 will present the experimental site, instrumental setup and methodologies; the results of the analysis will be described in Section 3, along with some discussion; finally, conclusions will be drawn in Section 4.

\section{Instruments and methods}

\subsection{Experimental site}

This study took place at the facilities of the Environmental Protection Agency (ARPA) of the Aosta Valley, a region located in the Northwestern Italian Alps (Fig. 1), at the atmospheric observatory of Aosta-Saint-Christophe (WIGOS ID 0-380-5-1, 45.74 ${ }^{\circ} \mathrm{N}, 7.36^{\circ} \mathrm{E}$, $570 \mathrm{~m}$ a.s.1). The station is located about $2.5 \mathrm{~km}$ east of Aosta, a 35,000-inhabitant town, at the bottom of the main valley. The valley lies in the W-E direction, and the site is surrounded on the northern and southern sides by mountains up to $3500 \mathrm{~m}$ high. The site area can be classified as semi-rural, partly influenced by anthropogenic aerosols locally emitted by human activities (such as vehicular traffic, domestic heating, steel production), and by 


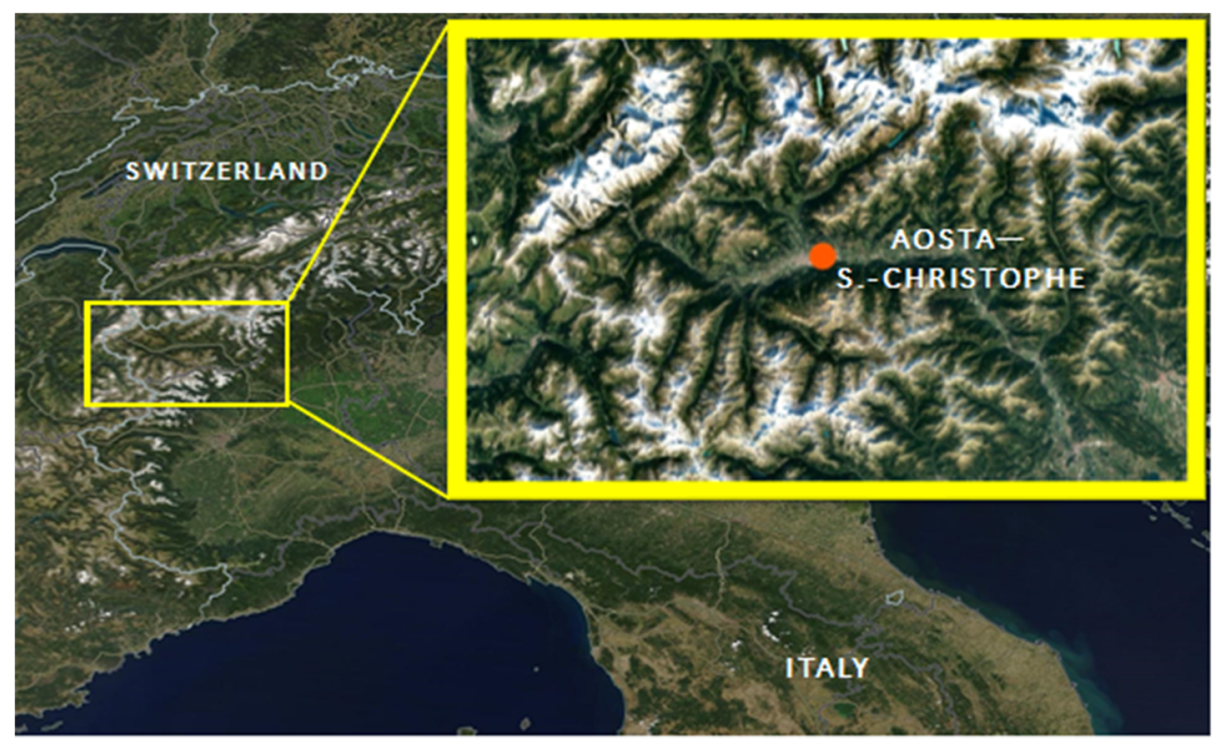

Fig. 1 Satellite view (from Terra/MODIS corrected reflectance, true colour, taken on August $9^{\text {th }}$, 2020) of the study location (orange dot), at the bottom of the Aosta Valley (expanded box), in the Northwestern Italian Alps

pollution transported to the site from the adjacent Po Valley (Diémoz et al. 2019; Diémoz et al. 2019; Diémoz et al. 2021); advections of Saharan dust from Northern Africa also occur occasionally (Diémoz et al. 2014). The meteorological conditions are typical of a mountain valley, with frequent thermally driven or dry downslope (Foehn) winds. Thermal inversions are very common in winter.

The main instruments used for this study are the sky radiometer POM-02 (manufactured by PREDE Co., Ltd., Japan) and a co-located Automated Lidar Ceilometer (ALC) CHM15k-Nimbus (manufactured by Lufft $\mathrm{GmbH}$, Germany). Three pyranometers were also used to ensure radiative closure at ground between measurements of surface horizontal irradiance and the corresponding radiative transfer simulations.

\subsection{Sky radiometer POM-02}

The POM-02 sky radiometer is a narrow-band filter radiometer that consists of two collimator tubes with solid-state sensors, mounted on a rotating support to track the Sun or point to different directions in the sky. It is designed to measure direct solar irradiance and diffuse sky radiances at different wavelengths: $315,340,380,400,500,675,870,940,1020,1627$ and $2200 \mathrm{~nm}$. The full widths at half maximum are $3.0 \mathrm{~nm}$ at near ultraviolet wavelengths, $10 \mathrm{~nm}$ in the visible range, $20 \mathrm{~nm}$ in the near infrared (Kudo et al. 2021). The diffuse radiances can be measured at different angles with two observation geometries: the almucantar plane (ALM, maintaining the instrument at a constant elevation angle and varying its azimuth angle) and the principal plane (PPL, maintaining a constant azimuth angle and varying the elevation). This instrument is part of the European SKYNET Radiometers Network (EuroSkyRad, http://www.euroskyrad.net/index.html, last access April 6, 2021) and is calibrated on site with the Improved Langley method, described in detail by Campanelli et al. (2004) and Campanelli et al. (2007). Its accuracy has been certified during international 
campaigns, by comparison with reference instruments (Kazadzis et al. 2018). Columnar aerosol optical properties are retrieved from solar radiation measurements, for cloudless conditions, using the inversion algorithm Skyrad pack MRI (Meteorological Research Institute) version 2, briefly indicated as MRIv2. This algorithm, described in more detail in Kudo et al. (2021), is based on an optimisation procedure that calculates the particle complex refractive index and the volume size distribution from the sky radiometer observations. Thereafter, the aerosol scattering phase function (and asymmetry factor), its optical depth and single scattering albedo are also calculated. The output of the inversion process includes AOD, SSA, phase function, asymmetry factor and complex refractive index at 340, 380, 400, 500, 675, 870 and $1020 \mathrm{~nm}$, and volume size distribution. The Skyrad MRI retrievals were proved to be reliable, through the comparison with retrievals obtained from other algorithms or with in situ measurements collected during field campaigns (Kudo et al. 2021). Moreover, we compared the columnar properties obtained from Skyrad MRIv2, in some stations of the EuroSkyRad network, to co-located retrievals from the AERONET network. This analysis showed a good agreement between AERONET and MRIv2 retrievals, and will be addressed in a future paper.

\subsection{Automated Lidar Ceilometer}

An Automated Lidar Ceilometer (ALC) CHM15k-Nimbus is used to obtain the information on the aerosol vertical distribution in the lower layers of the atmosphere (up to $15 \mathrm{~km}$ above the surface), which is not available from the columnar properties retrieved by the sky radiometer. The ALC relies on a low-power laser pulse $(1064 \mathrm{~nm}, 6.5-7 \mathrm{kHz})$ which is emitted towards the zenith and is scattered back to the instrument by the atmosphere. At the operating wavelength, backscattering is dominated by aerosol and cloud particles. The maximum temporal resolution of the system is $15 \mathrm{~s}$, while the vertical resolution is $15 \mathrm{~m}$. We usually downscale the ALC data to $75 \mathrm{~m}$ averages over the vertical coordinate and to $5 \mathrm{~min}$ over time to increase the signal-to-noise ratio. The instrument is part of the Italian network ALICEnet (http://www.alice-net.eu/, last access April 7, 2021) and the European network E-Profile (https://e-profile.eu/\#/cm_profile, last access April 7, 2021). The main limitations of this instrument are (a) the partly missing overlap between the field of view of the receiver and the laser beam in the lowest layers and (b) total signal extinction above thick clouds. The partial overlap is accounted for with a correction function provided by the manufacturer. The absolute calibration of the ALC is performed with the backward Klett method in clear-sky nights (Fernald 1984; Klett 1985). Once the lidar calibration constant is obtained, particle backscattering and extinction coefficients $\left(\beta_{p}, \alpha_{p}\right)$ are estimated for all times and sky conditions based on a forward Klett method (Wiegner and Geiß 2012). This solving technique requires an independent estimate of the lidar ratio (i.e. the ratio $L R=\frac{\alpha_{p}}{\beta_{p}}$ ). Instead of using an a priori fixed value of $L R$, we employ the functional relationships by Dionisi et al., 2018, relating $L R$ and $\beta_{p}$ (Dionisi et al. 2018). These relationships are obtained with a two-step approach: first, a large set of aerosol optical and physical properties is generated by randomly varying, within the typical ranges of continental particles (and partly accounting for dust-like, non-spherical particles), the aerosol size distribution and composition. Then, the results of the corresponding aerosol scattering simulations are fitted with polynomial functions linking key variables such as aerosol backscatter, extinction, surface area, and volume. Operatively, an iterative procedure is followed: $L R$ is first set to an initial value of $38 \mathrm{sr}$ (average value from the functional relationships), and the backscattering coefficient $\beta_{p}$ is retrieved; in the following steps, $\beta_{p}$ is used to determine an 
altitude-dependent lidar ratio, and the process is repeated until convergence in the vertically integrated backscatter is reached. The extinction coefficient $\alpha_{p}$ is derived at each step using the functional relationships.

The use of a low-power laser beam with an operating wavelength of $1064 \mathrm{~nm}$ could raise possible concerns about the capability of the instrument to correctly detect the aerosol layers, especially when fine particles are dominant. These issues are analysed in more depth in Section 3.4. Previous studies (Dionisi et al. 2018; Diémoz et al. 2019; Barragan et al. 2020; Diémoz et al. 2021), by the way, have already demonstrated the efficacy of this technique, by comparing its retrievals to independent observations from other instruments (such as sky radiometers or research lidars).

\subsection{Pyranometers}

Three ground-based pyranometers were used: two pyranometers model DPA153, manufactured by LSI Lastem s.r.l., Italy, and a model CMP-21 by Kipp \& Zonen. The latter is calibrated every 2 years at Physikalisch-Meteorologisches Observatorium Davos / World Radiation Center (PMOD/WRC) and provides accurate and stable measurements (Federico et al. 2017). The other two instruments were calibrated against the model CMP-21. The pyranometers observations are corrected for the thermal offset (Dutton et al. 2001; Haeffelin et al. 2001). Each of the instruments was used to measure one of the components of the horizontal shortwave $(\sim 300-3000 \mathrm{~nm})$ irradiance, at 5-min resolution. The CMP-21 was used to measure the upward diffuse component, while the others measured the global downward and diffuse downward (using a shadowband to obscure the Sun) components. From the last two quantities it was possible to derive the direct beam irradiance, which was not directly measured. Keeping in mind that the shadowband covers also a small region of the sky, the diffuse downward irradiance values were corrected by a factor provided by the shadowband manufacturer (LSI-LASTEM 2012). The pyranometer measurements were associated with an uncertainty which resulted from an internal investigation that took place at ARPA Valle d'Aosta: the uncertainty of the CMP-21 (about 1\%) was extracted from the calibration certificate, and was used to propagate the uncertainty on the two DPA153. This showed a dependence on the Sun azimuth angle, being maximum in the early morning.

\subsection{Method}

The aerosol direct radiative effect was evaluated over the Aosta-Saint-Christophe site in two case studies, represented by two days with cloudless conditions and complete sky radiometer and ALC data. These two days were selected as representative of distinct aerosol conditions over the experimental site: in the first case, March $25^{\text {th }}, 2018$, an event of pollution transport from the Po Valley to the site was identified; in the second case, June $25^{\text {th }}$, 2019, an advection of Saharan dust occurred. The aerosol features in both cases are detailed in Sections 3.1.1 and 3.2.1, respectively. It is worth noting that, in these cases, one aerosol species is highly dominant, and the aerosol properties are well defined: the first case is characterised by secondary, mostly fine particles, whereas the second case is characterised by mostly coarse mineral particles. The chosen case studies are representative of common conditions occurring at the experimental site: advections of secondary aerosol from the Po Valley take place about 50\% of the time (Diémoz et al. 2019), and can lead to higher-thanaverage aerosol loads. Furthermore, since the Aosta Valley is close to the Mediterranean basin, transport of desert dust is not rare. Additionally, such a case study represents an interesting situation to assess the effect of coarse, asymmetrical particles, very different from the 
ones of secondary origin. The geographical provenance of the aerosol layers was verified by calculation of lagrangian backtrajectories (not shown), with the NOAA HYSPLIT tool (https://www.ready.noaa.gov/HYSPLIT.php, last access April 8, 2021). Both cases were also chosen because of quite high aerosol loads, to make the retrieval of the optical properties more reliable (Dubovik et al. 2000; Estellés et al. 2012). Cloudless conditions were checked by visual inspection of images from a co-located Total-Sky Camera.

For every case study, aerosol columnar properties were retrieved by inversion of the sky radiometer measurements (Section 2.2). Skyrad MRIv2 also requires some atmospheric or environmental variables as input, such as surface temperature, pressure and albedo, columnar ozone and the approximate aerosol vertical distribution. These quantities were set to the most accurate values available for the day, taken from other locally available datasets or inferred from satellite data, and are reported in Table 1. Surface effective albedo (Diémoz et al. 2013) was estimated from MERRA-2 satellite reanalysis (https://gmao.gsfc.nasa.gov/ reanalysis/MERRA-2/, last access April 8, 2021), together with soil use information available at ARPA Valle d'Aosta and data of spectrally dependent albedo over different surfaces taken from other studies (Feister and Grewe 1995; Roberts et al. 2004). In the first case study, the presence of snow on the slopes near to the site had to be considered for the estimation of the surface albedo.

The output of Skyrad MRIv2 was then used for the assessment of the shortwave aerosol direct radiative effect and the consequent heating rate. These were simulated with the libRadtran radiative transfer package (Emde et al. 2016), version 2.0.4, in cloudless conditions. This tool allows to calculate, at different altitudes, the global downward, diffuse downward and diffuse upward irradiances in the solar region of the spectrum (300-3000 nm) and the atmospheric heating rate caused by the presence of aerosol. The radiative transfer solver disort with 18 streams in pseudospherical approximation (Dahlback and Stamnes 1991) was used, and the Kato correlated-k approach (Kato et al. 1999) was adopted to parametrise the atmospheric transmittance in the whole shortwave band. The atmospheric profiles were taken from the U.S. Standard atmosphere (Anderson et al. 1986), and normalised to the temperature, pressure and columnar ozone measured locally. The Sun-Earth distance was specified, and the solar zenith angle was set according to the sky radiometer measurements.

The properties that are needed for the evaluation of the aerosol direct radiative effect are aerosol optical depth, single scattering albedo and asymmetry factor (or, for a more accurate description, the whole aerosol phase function). The aerosol description within the radiative transfer code was given in two different ways:

Table 1 Definitions of the environmental quantities required by Skyrad MRIv2

\begin{tabular}{lll}
\hline & Case study A & Case study B \\
\hline Columnar ozone & $409 \mathrm{DU}$ & $315 \mathrm{DU}$ \\
$\mathrm{T}_{\text {sfc }}$ & $286 \mathrm{~K}$ & $302.5 \mathrm{~K}$ \\
$\mathrm{P}_{\mathrm{atm}}$ & $943.0 \mathrm{hPa}$ & $958.8 \mathrm{hPa}$ \\
Columnar water vapour & $7.0 \mathrm{~mm}$ & $20.0 \mathrm{~mm}$ \\
Surface albedo & 0.3 & Spectrally variable (between \\
& & 0.04 at near UV and 0.25 at near IR) \\
Aerosol profile & Gaussian up to $3.5 \mathrm{~km}$ a.s.l. & Uniform up to $4.5 \mathrm{~km}$ a.s.l. \\
\hline
\end{tabular}


1. An accurate description, where all the information available from the Skyrad MRIv2 retrieval was used, including the spectral dependence of SSA and the full phase function. To overcome the limited range (i.e. $340-1020 \mathrm{~nm}$ ) of the MRIv2 output, the retrieval was reprocessed with the BroadBand Radiometer simulator software (BBR, part of Skyrad MRIv2 package) to extrapolate the AOD, SSA and phase function in the whole solar region of the spectrum at 50-nm intervals. These quantities were calculated on a physical basis, from the retrieved complex refractive index and size distribution, using the same kernels employed in the inversion procedure. The spectral aerosol extinction coefficient was calculated up to $6 \mathrm{~km}$ a.s.l. (assuming that the aerosol load is negligible at higher altitudes with respect to lower troposphere, as also confirmed by visual analysis of the ALC profiles) from the aerosol optical depth thus obtained, by scaling according to the normalised extinction profile obtained from the ALC. The other properties were assumed as constant with altitude, since the aerosol layer appears to be vertically well mixed. The aerosol phase function was expressed through the first 50 moments of its expansion as a series of Legendre polynomials.

2. An approximate description, which instead relied only on a spectral definition of the AOD (through the parameters of the Ångström law, $\tau(\lambda)=\beta \lambda^{-\alpha}$ ). Spectrally constant values of the SSA and the asymmetry factor $g$ (instead of the full phase function) were given to the model. The values of SSA and $g$ were set according to a spectral average of Skyrad MRIv2 outputs, and were also considered as constant with altitude. It is possible, instead, to define the vertical profile of AOD: this information, as before, was derived by ALC data.

The RTM simulations obtained using the accurate description of the aerosol properties have been compared to those obtained with the approximate one (Sections 3.1.4 and 3.2.4). In this way we tried to understand whether the different aerosol descriptions have a clear impact on the evaluation of its radiative effects, and therefore whether a complete and detailed description is necessary or a more approximate (but much faster and easier to obtain) one could be sufficient.

The aerosol properties are obtained every few minutes from the sky radiometer measurements. They were then aggregated on a hourly basis. The radiative transfer simulations were consequently carried out over these hourly intervals, using the averaged properties as input for the model. Daily-mean (sunrise to sunset) simulations were also performed.

The aerosol direct radiative effect (DRE) through a surface is defined as the difference between the net shortwave flux $\left(F_{\text {downward }}-F_{\text {upward }}\right)$ with and without aerosol (Ferrero et al. 2014; Srivastava et al. 2012):

$$
D R E_{z}=F_{z}^{a e r}-F_{z}^{w / o-a e r}
$$

The difference between the $D R E$ at the upper and lower limit of a layer of thickness $\Delta z$ expresses the power per unit area absorbed into the layer due to the presence of aerosol:

$$
\triangle D R E_{\Delta z}=D R E_{z+\Delta z}-D R E_{z}
$$

The radiative power absorbed is turned into heat, that warms the layer. So, using the first principle of thermodynamics in plane-parallel approximation, it is possible to calculate the instantaneous heating rate of the layer:

$$
H R=\frac{d T}{d t}=\frac{1}{\rho c_{p}} \frac{\Delta D R E_{\Delta z}}{\Delta z}
$$

where $c_{p}$ is the specific heat at constant pressure of air and $\rho$ its density. LibRadtran is able to directly calculate the heating rate of a layer, so the net heating rate due to aerosol has 
been calculated as the difference between the values obtained including and excluding the aerosol from the atmosphere.

As a final step, the irradiances simulated at the surface with libRadtran were compared to pyranometer observations in order to ensure their accuracy. Unfortunately, pyranometer data were not available for the case study of June $25^{\text {th }}, 2019$. This comparison was thus performed only in the first case study. To provide an experimental reference for the simulations done by excluding the aerosol, a cloudless day with very clean conditions was chosen close to the investigated day. That was the case of March $23^{\text {rd }}, 2018$, which was characterised by a very low aerosol load (AOD $<0.05$ at $500 \mathrm{~nm}$ ) throughout the day.

\section{Results and discussion}

The results are presented for the two case studies described in Section 2.5. First, the aerosol direct radiative effect is calculated at the surface (SFC) and at the top of atmosphere (TOA). From these two quantities it is possible to derive (Eq. 2) the net power absorbed by aerosol in the whole atmospheric layer (ATM). Then, the vertically resolved atmospheric heating rate is calculated in each of the atmospheric layers defined in the RTM: the first layer goes from the surface (570 $\mathrm{m}$ a.s.l.) to $1000 \mathrm{~m}$ a.s.l., and the others are $0.5 \mathrm{~km}$ thick up to $8 \mathrm{~km}$ a.s.l.

\subsection{Case study A: March $25^{\text {th }}, 2018$}

\subsubsection{Summary of the aerosol characteristics}

The aerosol load in case study A consists in secondary particles transported from the Po Valley over the Aosta-Saint-Christophe site. The average daily $\mathrm{PM}_{10}$ concentration at ground level is $30 \mu \mathrm{g} \mathrm{m}^{-3}$. The particle volume distribution is dominated by a fine mode, peaked at a radius of about $0.2 \mu \mathrm{m}$. The AOD shows a decreasing trend during the day (Fig. 2), sharper during the morning and more gradual thereafter, from about 0.5 to 0.2 (at $500 \mathrm{~nm}$ ); the Ångström exponent gradually increases from 1.5 to about 1.75 , in agreement with values found elsewhere for fine aerosol of secondary origin (Dubovik et al. 2002). The SSA shows a slightly decreasing trend in time, from about 0.93 to 0.88 at $500 \mathrm{~nm}$; this may be due to the drying of hygroscopic aerosol during the day, which leaves more absorbing particles (Tao et al. 2014). From the ALC data (Fig. 3) it is possible to conclude that the aerosol
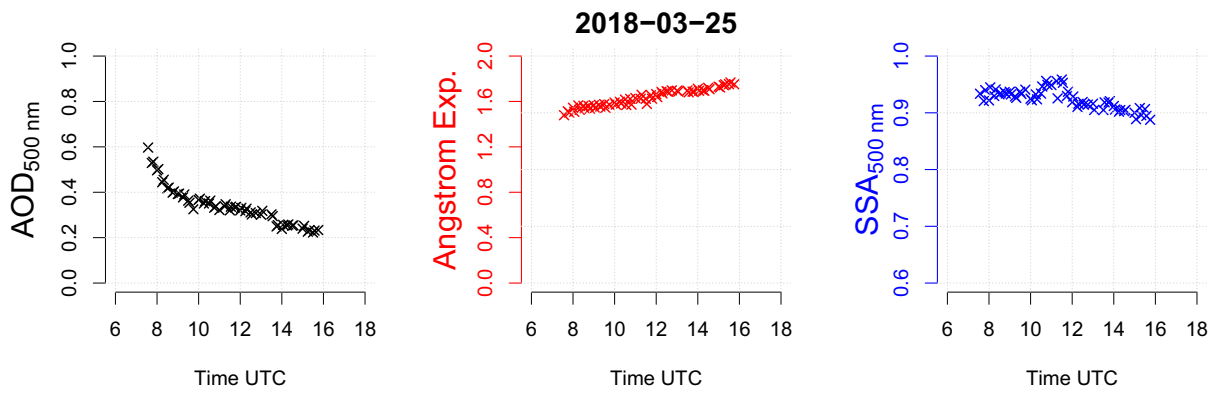

Fig. 2 Daily retrievals of AOD, Ångström exponent and SSA from the sky radiometer, case study A. The Ångström exponent is calculated using all the wavelengths of the MRIv2 retrieval (from 340 to $1020 \mathrm{~nm}$ ) 


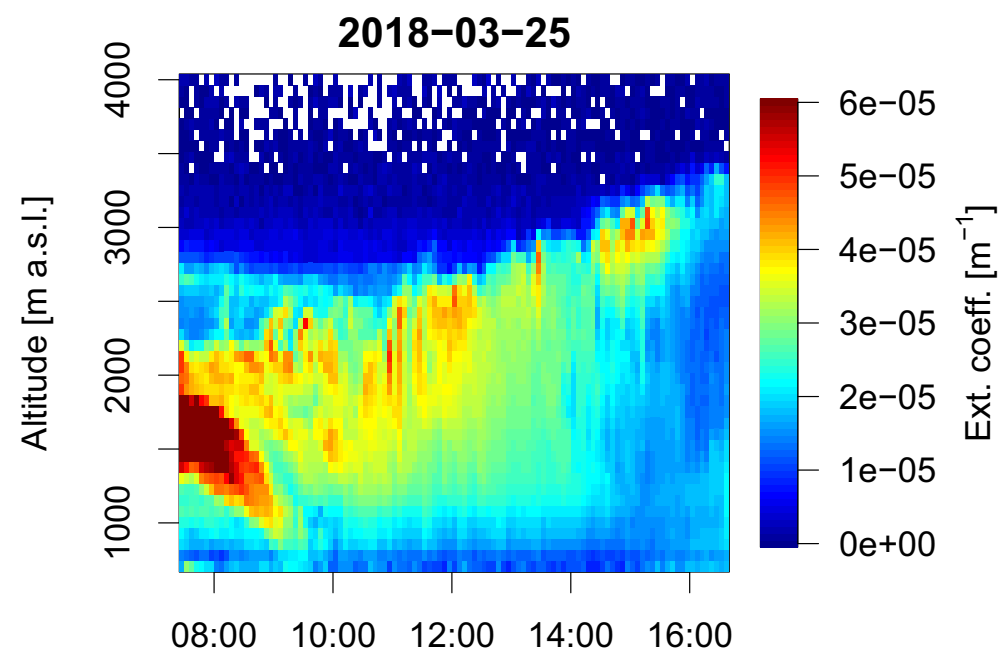

Time UTC

Fig. 3 Profile of the aerosol extinction coefficient (in $\mathrm{m}^{-1}$, colour scale) from ALC data, case study A, as a function of time and altitude above sea level. Only the hours between sunrise and sunset are shown

laden layer is confined below $2500 \mathrm{~m}$ a.s.l. in the morning, with a roughly bell-shaped profile; it extends up to $3500 \mathrm{~m}$ a.s.l. during the day, with a more uniform distribution. This is consistent with the growth of the mixed layer during the day. The aerosol extinction coefficient was found to be practically negligible and mainly affected by random noise above 4 $\mathrm{km}$ a.s.l.: therefore, it has been set to zero above this altitude.

\subsubsection{Aerosol DRE}

Table 2 and Fig. 4 show, respectively, the aerosol DRE in the different hourly intervals and in the daily average simulation. As expected, the presence of aerosols has a dimming effect at the surface, which in this case is higher in the early morning. This can be simply attributed to the higher aerosol load; another explanation could be that, at lower solar elevations, more radiation is scattered away by aerosols, because of the longer optical path length. At TOA, in most cases the aerosol induces a small negative radiative effect, which means a net cooling of the overall system; this effect is more pronounced at lower solar elevations, while around midday it can be even slightly positive. Inside the atmospheric layer, the power per unit area absorbed by aerosol remains around $25-30 \mathrm{~W} \mathrm{~m}^{-2}$ : the decrease in the aerosol load is balanced by the increase in its absorptive capacity. On a daily perspective, the presence of aerosol has a small negative DRE at TOA, and a considerable dimming effect at the surface. The values of the DRE at the surface and TOA, and the power absorbed in the atmosphere, are in agreement with other results obtained in similar contexts (Ferrero et al. 2014).

\subsubsection{Atmospheric heating rate}

Figure 5 and Table 3 present, respectively, the daily and hourly averages of the atmospheric heating rates due to the presence of aerosol. In Fig. 5 the daily-averaged aerosol extinction 
Table 2 Average aerosol DRE in the different hourly intervals, case study A

\begin{tabular}{llllllllll}
\hline Hour UTC & $7-8$ & $8-9$ & $9-10$ & $10-11$ & $11-12$ & $12-13$ & $13-14$ & $14-15$ & $15-16$ \\
\hline TOA $\left[\mathrm{W} \mathrm{m}^{-2}\right]$ & -17.9 & -11.1 & -4.5 & -1.8 & -1.5 & 3.2 & 0.7 & -1.2 & -4.3 \\
ATM $\left[\mathrm{W} \mathrm{m}^{-2}\right]$ & 29.6 & 29.2 & 28.8 & 28.0 & 24.3 & 32.5 & 29.0 & 25.5 & 23.0 \\
SFC $\left[\mathrm{W} \mathrm{m}^{-2}\right]$ & -47.5 & -40.2 & -33.2 & -29.7 & -25.8 & -29.3 & -28.3 & -26.6 & -27.3 \\
\hline
\end{tabular}

coefficient (at $1064 \mathrm{~nm}$, obtained from the ALC) is also plotted. The maximum heating rates, between 1 and $1.5 \mathrm{~K} \mathrm{day}^{-1}$, are mostly found between 2 and $3 \mathrm{~km}$ a.s.l.; this is true even when the highest aerosol extinction coefficient is located below $2 \mathrm{~km}$ a.s.l. As a result, the daily-averaged heating rates are slightly shifted upwards with respect to the average aerosol vertical distribution. This can be explained by the fact that the solar flux is strongly reduced in the lowest layers, due to extinction in the above ones. Hence, despite a large aerosol load, the lowest layers experiment a slightly reduced warming. The values of the heating rates are consistent with results obtained by other studies in similar contexts (such as Ferrero et al. (2014)) or in different regions of the world (Srivastava et al. 2012, keeping in mind that aerosol load at Aosta-Saint-Christophe is generally much lower than in highly urbanised areas).

\section{8-03-25}

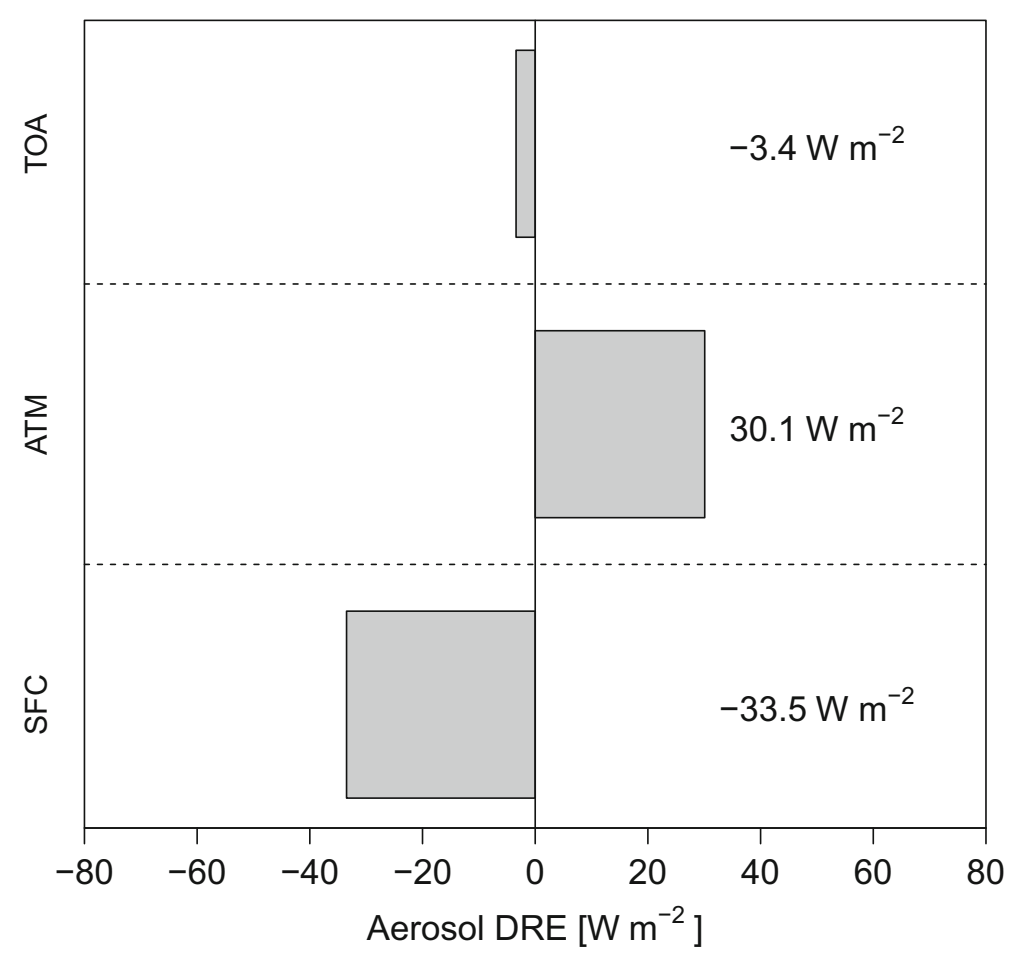

Fig. 4 Average daily aerosol DRE, case study A, at the top of the atmosphere (TOA), in the atmospheric layer (ATM) and at the surface (SFC) 


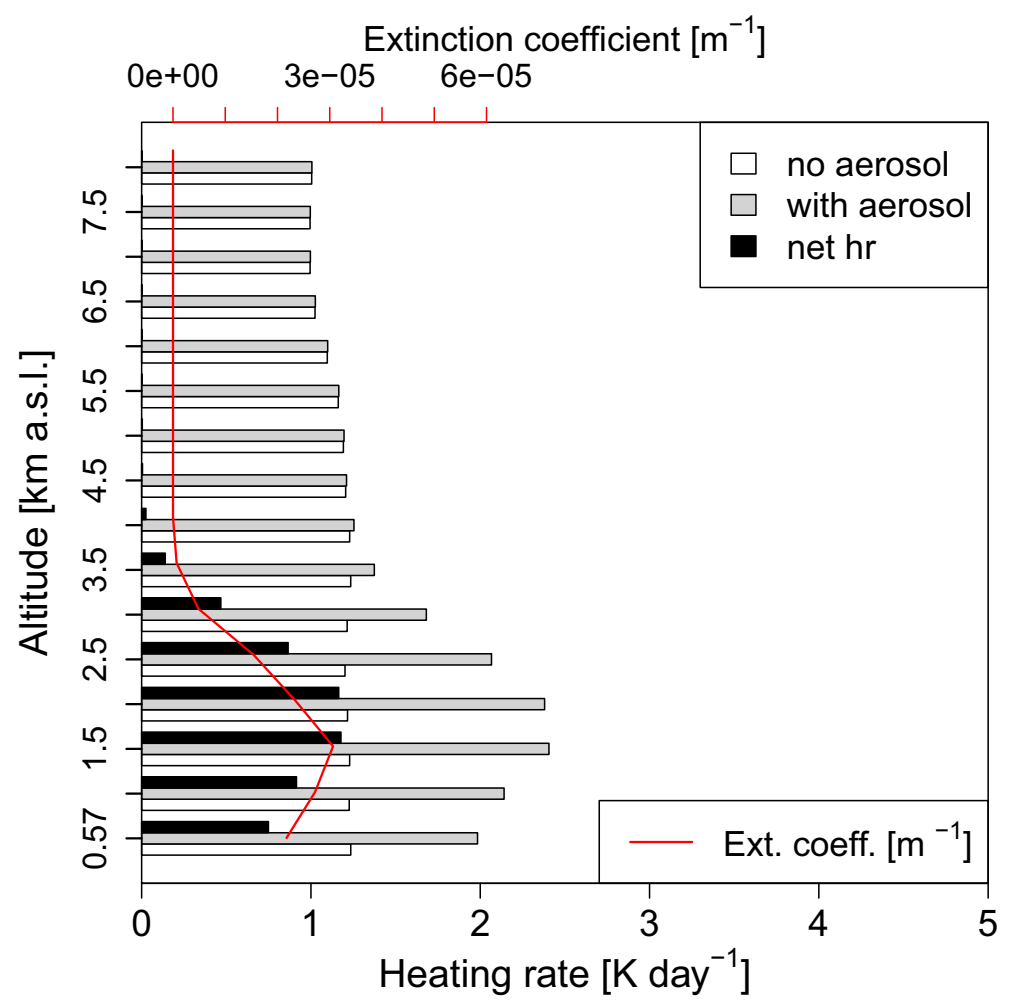

Fig. 5 Average daily atmospheric HR, case study A. The black bars represent the net HR due to aerosol in every layer. The profile of the aerosol extinction coefficient (red line) is also shown

Table 3 Average atmospheric heating rates in the different hourly intervals, case study A. Values are in $\mathrm{K} \mathrm{day}^{-1}$. The values above $6 \mathrm{~km}$ a.s.l. are close to 0 and are omitted

\begin{tabular}{llllllllll}
\hline Hour UTC & $7-8$ & $8-9$ & $9-10$ & $10-11$ & $11-12$ & $12-13$ & $13-14$ & $14-15$ & $15-16$ \\
\hline $5.5-6 \mathrm{~km}$ & 0.01 & 0.00 & 0.00 & 0.00 & 0.00 & 0.00 & 0.00 & 0.00 & 0.00 \\
$5-5.5 \mathrm{~km}$ & 0.01 & 0.01 & 0.00 & 0.00 & 0.00 & 0.00 & 0.00 & 0.00 & 0.00 \\
$4.5-5 \mathrm{~km}$ & 0.01 & 0.01 & 0.01 & 0.00 & 0.00 & 0.00 & 0.00 & 0.00 & 0.01 \\
$4-4.5 \mathrm{~km}$ & 0.03 & 0.02 & 0.02 & 0.02 & 0.02 & 0.02 & 0.02 & 0.02 & 0.04 \\
$3.5-4 \mathrm{~km}$ & 0.08 & 0.07 & 0.07 & 0.07 & 0.06 & 0.08 & 0.14 & 0.25 & 0.38 \\
$3-3.5 \mathrm{~km}$ & 0.30 & 0.33 & 0.35 & 0.32 & 0.37 & 0.56 & 0.65 & 0.78 & 0.87 \\
$2.5-3 \mathrm{~km}$ & 0.77 & 0.82 & 0.94 & 0.85 & 0.90 & 1.25 & 1.15 & 1.03 & 0.87 \\
$2-2.5 \mathrm{~km}$ & 1.48 & 1.25 & 1.26 & 1.24 & 1.09 & 1.43 & 1.16 & 0.88 & 0.63 \\
$1.5-2 \mathrm{~km}$ & 1.37 & 1.26 & 1.09 & 1.15 & 0.89 & 1.15 & 0.95 & 0.71 & 0.53 \\
$1-1.5 \mathrm{~km}$ & 0.66 & 0.86 & 0.83 & 0.81 & 0.61 & 0.82 & 0.69 & 0.55 & 0.47 \\
$0.57-1 \mathrm{~km}$ & 0.42 & 0.58 & 0.71 & 0.61 & 0.46 & 0.63 & 0.54 & 0.45 & 0.46 \\
\hline
\end{tabular}




\subsubsection{Use of the approximate aerosol description}

Aerosol DRE and atmospheric heating rates were also simulated using the approximate aerosol description, where the spectral dependency of the SSA and the complete information about the phase function are not taken into account, as explained in Section 2.5. The average daily DRE at TOA calculated using this description is $-2.0 \mathrm{~W} \mathrm{~m}^{-2}$, i.e. $1.4 \mathrm{~W} \mathrm{~m}^{-2}$ higher than in the accurate simulation; at the surface, the difference is minimal: $-33.6 \mathrm{~W} \mathrm{~m}^{-2}$ using the simplified description versus $-33.5 \mathrm{~W} \mathrm{~m}^{-2}$ using the complete one. So the net DRE inside the atmospheric column changes from $+30.1 \mathrm{~W} \mathrm{~m}^{-2}$ with accurate properties to $+31.6 \mathrm{~W} \mathrm{~m}^{-2}$ using approximate properties. The absolute differences in the hourly DRE values are never greater than $3 \mathrm{~W} \mathrm{~m}^{-2}$.

The differences in the atmospheric heating rates obtained with the two descriptions are lower than $0.15 \mathrm{~K} \mathrm{day}^{-1}$ at all altitudes for the maximum values, and in general not greater than $10 \%$ in the layers with more significant warming, for both the hourly average and daily average simulations.

We can thus conclude that, in this case study, the method used to describe the aerosol optical properties plays a minor role.

\subsection{Case study B: June $25^{\text {th }}, 2019$}

\subsubsection{Summary of the aerosol characteristics}

The aerosol load on case study B consists on dust particles transported from Northern Africa. The average daily $\mathrm{PM}_{10}$ concentration at ground level is $24 \mu \mathrm{g} \mathrm{m}^{-3}$. It is not surprising that this value is lower than in case study A, for two main reasons: as demonstrated in other studies (Diémoz et al. 2019), advections of fine particles from the Po Valley can occasionally lead to very high aerosol concentrations at the bottom of the valley and even at higher altitudes; moreover, both in the case of transported dust and advection from the Po Valley, the heavier aerosol burden can sometimes be located in the layers above the surface, rather than at ground level. In this particular case, the deposition at ground level was more pronounced in the following days, with daily-averaged $\mathrm{PM}_{10}$ values higher than $40 \mu \mathrm{g} \mathrm{m}^{-3}$.

The particle volume distribution shows an evident coarse mode peaked at about 2-4 $\mu \mathrm{m}$. The AOD at $500 \mathrm{~nm}$ decreases from about 0.4 in the early morning to 0.2 at midday, increasing again to about 0.3 in the afternoon. Overall, the aerosol properties can be split before and after midday (Fig. 6): the Ångström exponent, for example, sharply decreases from above 1 down to about 0.6 (a typical value for desert dust, Dubovik et al. (2002)), and remains fairly constant thereafter; SSA at $500 \mathrm{~nm}$ is slightly higher than 0.9 before midday, and lower after then, showing an increase with wavelength that is a common feature of desert dust. From the ALC data (Fig. 7) it can be observed that the aerosol is confined below $3500 \mathrm{~m}$ a.s.l. in the morning, while in the afternoon it reaches almost $5000 \mathrm{~m}$ a.s.l. and is more uniformly distributed. These differences can be likely related to the dust concentration reaching its climax during the afternoon. In this case, the aerosol extinction coefficient has been found to be determined only by random noise above $5 \mathrm{~km}$ a.s.l., and it has been set to zero above this altitude. Between 11:00 and 12:00 UTC, some very thin cirrus clouds, affecting the retrievals of aerosol properties, are detected from the sky-camera images: hence, the whole hourly interval is excluded from the analysis. 

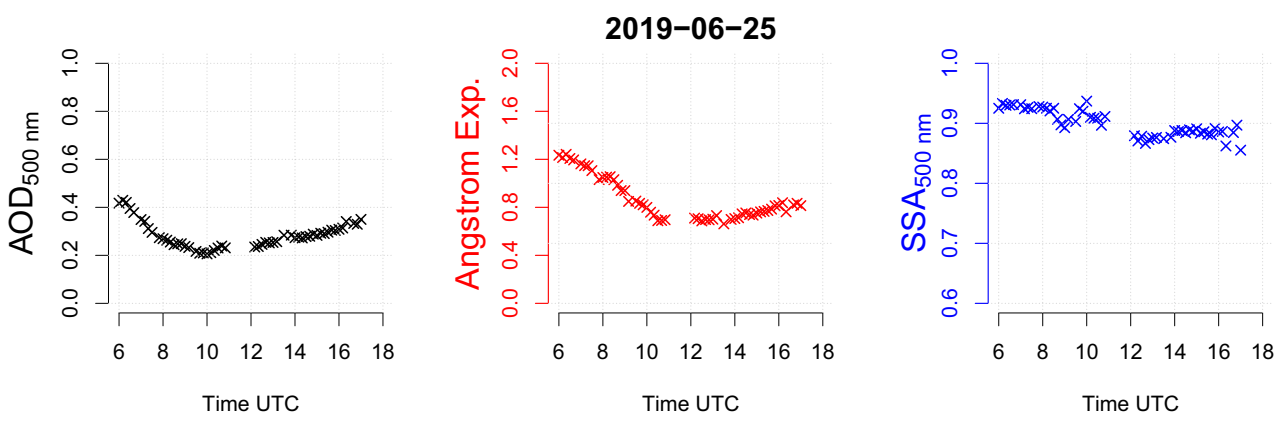

Fig. 6 Daily retrievals of AOD, Ångström exponent and SSA from the sky radiometer, case study B. The Ångström exponent is calculated using all the wavelengths of the MRIv2 retrieval (from 340 to $1020 \mathrm{~nm}$ ). As explained in Section 3.2.1, the interval 11-12 UTC has been removed due to the presence of thin clouds

\subsubsection{Aerosol DRE}

Table 4 and Fig. 8 present, respectively, the hourly and daily average aerosol DRE for the second case study. The surface dimming in this case is again more evident at high solar zenith angles, and reaches values as large as $-50 \mathrm{~W} \mathrm{~m}^{-2}$. As in the previous case, this is in agreement with the daily variations in AOD, but can also be explained by greater scattering when solar zenith angle is larger. At TOA, aerosol DRE is negative, and shows a similar behaviour to the one of the previous case, being more negative at higher solar zenith angles. Inside the atmospheric layer, the absorbed power is quite different from the morning $(\sim 20$ $\left.\mathrm{W} \mathrm{m}^{-2}\right)$ to the afternoon hours $\left(\sim 35 \mathrm{~W} \mathrm{~m}^{-2}\right)$ : it is very likely that this is related to the lower SSA after midday. On a daily perspective, the DRE at TOA is more negative than in case A, inducing a higher global cooling. These values, as in the previous case, agree with results

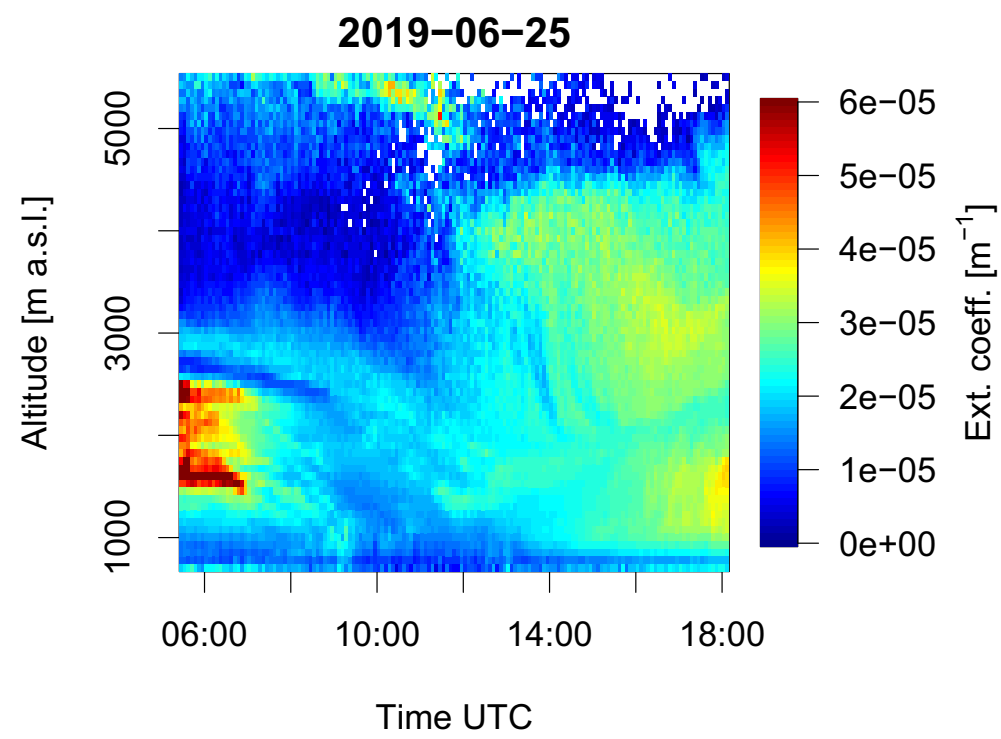

Fig. 7 Profile of the aerosol extinction coefficient (in $\mathrm{m}^{-1}$, colour scale) from ALC data, case study B 
Table 4 Average aerosol DRE in the different hourly intervals, case study B

\begin{tabular}{|c|c|c|c|c|c|c|c|c|c|c|}
\hline Hour UTC & $6-7$ & $7-8$ & $8-9$ & $9-10$ & $10-11$ & $12-13$ & $13-14$ & $14-15$ & $15-16$ & $16-17$ \\
\hline TOA $\left[\mathrm{W} \mathrm{m}^{-2}\right]$ & -22.1 & -14.8 & -8.8 & -5.3 & -3.5 & -1 & -3.2 & -8.3 & -12.6 & -17.6 \\
\hline ATM $\left[\mathrm{W} \mathrm{m}\right.$ m $\left.^{-2}\right]$ & 20.2 & 20.0 & 20.0 & 19.7 & 19.8 & 35 & 38.3 & 33.4 & 33.9 & 34.1 \\
\hline $\mathrm{SFC}\left[\mathrm{W} \mathrm{m}{ }^{-2}\right]$ & -42.3 & -34.8 & -28.8 & -25.0 & -23.3 & -36 & -41.6 & -41.7 & -46.5 & -51.7 \\
\hline
\end{tabular}

obtained in other studies. In Meloni et al. (2015), for example, Meloni et al. found higher surface dimming and higher net cooling at TOA due to desert dust. By the way, this could be partly caused by greater aerosol load and higher SSA attributed to the particles in their simulations.

\subsubsection{Atmospheric heating rate}

Figure 9 and Table 5 show, respectively, the daily and hourly averages of the atmospheric heating rates due to the presence of aerosol in the second case study. In this case, the warming is more distributed across the different layers, and the maximum values are slightly lower than in the previous case, about $1.0-1.1 \mathrm{~K} \mathrm{day}^{-1}$. This is in agreement with the aerosol load being more distributed along the vertical coordinate, which can also be explained by

\section{9-06-25}

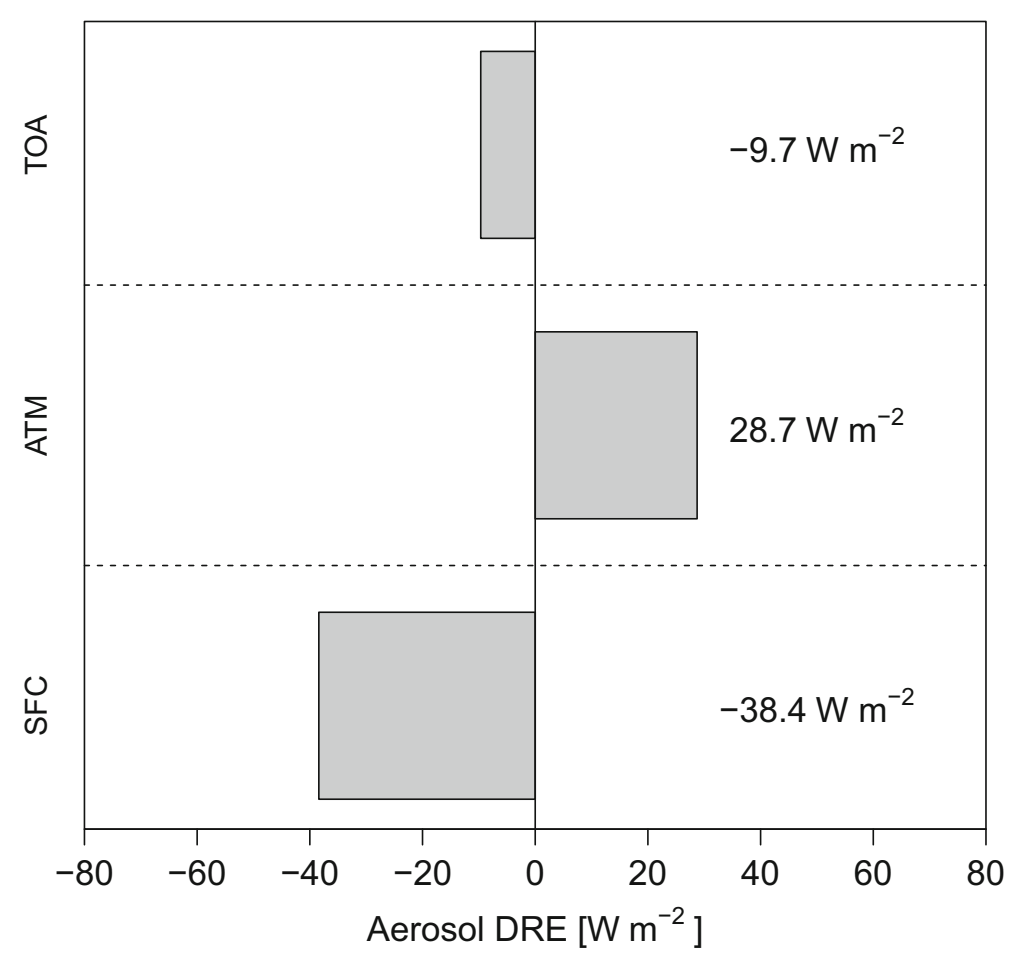

Fig. 8 Average daily aerosol DRE, case study B 


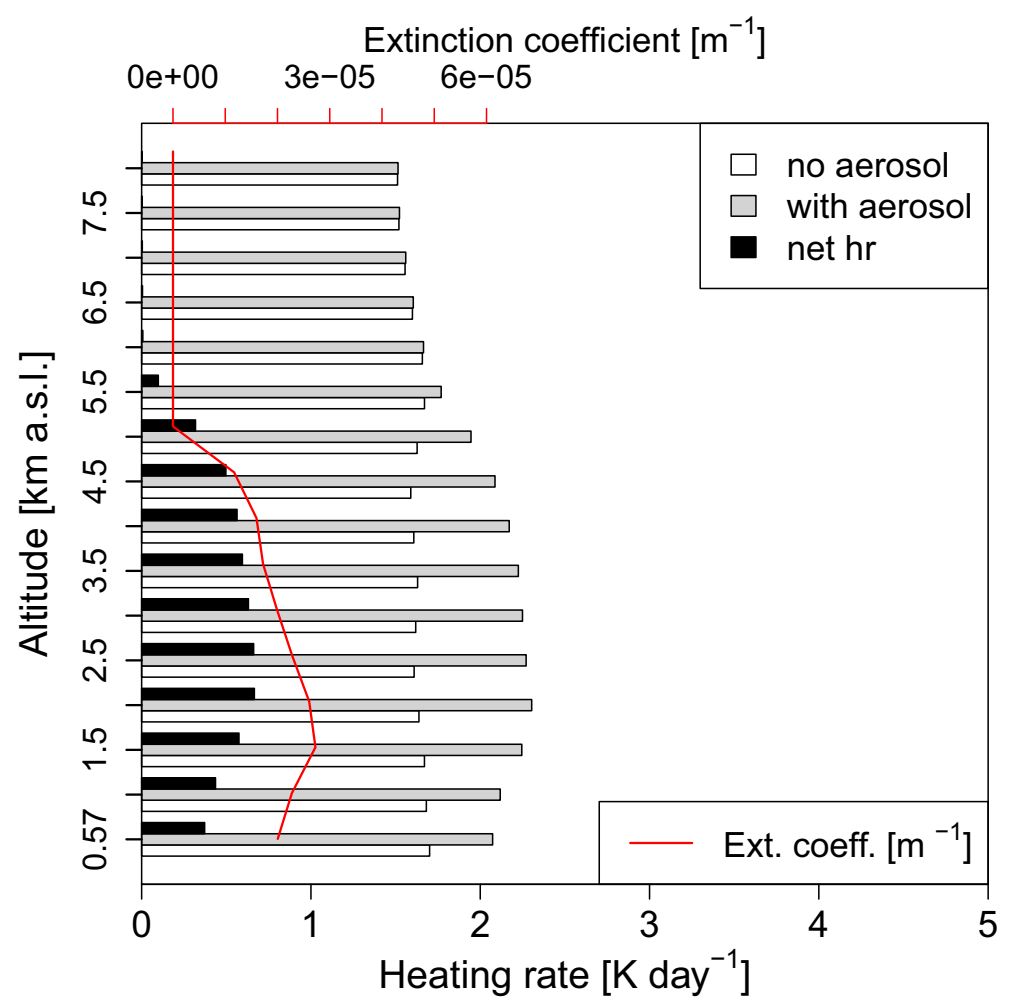

Fig. 9 Average daily atmospheric HR, case study B. The profile of the aerosol extinction coefficient is also shown

Table 5 Average atmospheric heating rates in the different hourly intervals, case study B. Values are in $\mathrm{Kday}^{-1}$. The values above $6 \mathrm{~km}$ a.s. 1 are close to 0 and are omitted

\begin{tabular}{lllllllllll}
\hline Hour UTC & $6-7$ & $7-8$ & $8-9$ & $9-10$ & $10-11$ & $12-13$ & $13-14$ & $14-15$ & $15-16$ & $16-17$ \\
\hline $5.5-6 \mathrm{~km}$ & 0.09 & 0.10 & 0.11 & 0.10 & 0.09 & 0.12 & 0.11 & 0.07 & 0.05 & 0.04 \\
$5-5.5 \mathrm{~km}$ & 0.24 & 0.29 & 0.30 & 0.27 & 0.26 & 0.37 & 0.39 & 0.31 & 0.25 & 0.25 \\
$4.5-5 \mathrm{~km}$ & 0.26 & 0.32 & 0.28 & 0.27 & 0.32 & 0.67 & 0.82 & 0.71 & 0.65 & 0.64 \\
$4-4.5 \mathrm{~km}$ & 0.19 & 0.22 & 0.19 & 0.18 & 0.27 & 0.91 & 1.11 & 0.94 & 0.95 & 0.91 \\
$3.5-4 \mathrm{~km}$ & 0.23 & 0.29 & 0.27 & 0.24 & 0.29 & 0.88 & 1.02 & 0.90 & 0.96 & 0.97 \\
$3-3.5 \mathrm{~km}$ & 0.37 & 0.40 & 0.42 & 0.41 & 0.40 & 0.79 & 0.84 & 0.80 & 0.87 & 0.90 \\
$2.5-3 \mathrm{~km}$ & 0.57 & 0.48 & 0.48 & 0.53 & 0.51 & 0.76 & 0.77 & 0.70 & 0.74 & 0.75 \\
$2-2.5 \mathrm{~km}$ & 0.67 & 0.53 & 0.48 & 0.51 & 0.53 & 0.73 & 0.74 & 0.62 & 0.62 & 0.62 \\
$1.5-2 \mathrm{~km}$ & 0.50 & 0.44 & 0.47 & 0.44 & 0.44 & 0.65 & 0.65 & 0.53 & 0.53 & 0.53 \\
$1-1.5 \mathrm{~km}$ & 0.27 & 0.34 & 0.40 & 0.40 & 0.34 & 0.47 & 0.51 & 0.43 & 0.44 & 0.42 \\
$0.57-1 \mathrm{~km}$ & 0.20 & 0.29 & 0.36 & 0.39 & 0.29 & 0.35 & 0.44 & 0.38 & 0.39 & 0.35 \\
\hline
\end{tabular}


stronger vertical mixing in a summer situation. The maximum values are reached after midday in the layers between 3.5 and $5 \mathrm{~km}$ a.s.1., consistently with the decrease in SSA highlighted in Section 3.2.1. The warming shows again a certain shift with respect to the aerosol vertical distribution, and this is particularly evident in the afternoon when the heating is stronger; in the lowest layers, despite a high aerosol extinction coefficient, the warming is reduced.

The atmospheric heating found in this case is in agreement with values obtained in other studies, for the particular case of desert dust (e.g. Meloni et al. 2015).

\subsubsection{Use of the approximate aerosol description}

In this case, the average daily DRE at TOA calculated using the approximate aerosol description is $-8.6 \mathrm{~W} \mathrm{~m}^{-2}$, i.e. $1.1 \mathrm{~W} \mathrm{~m}^{-2}$ higher than the value obtained with the accurate spectral aerosol properties; at the surface, the calculated DRE is $-40.2 \mathrm{~W} \mathrm{~m}^{-2}$ using the approximate description versus $-38.4 \mathrm{~W} \mathrm{~m}^{-2}$ using the accurate one. The resulting net DRE inside the atmospheric column changes from $+28.7 \mathrm{~W} \mathrm{~m}^{-2}$ with accurate properties to $+31.6 \mathrm{~W} \mathrm{~m}^{-2}$ using the approximate ones. In the case of hourly DRE simulations, the absolute differences are never greater than $5 \mathrm{~W} \mathrm{~m}^{-2}$.

For what concerns the atmospheric heating rates obtained with the two different aerosol descriptions, in this case the differences are slightly higher. In particular, using the approximate description leads to systematically higher heating rates. Some hourly average differences can be as high as $0.2 \mathrm{~K} \mathrm{day}^{-1}$, with a relative difference up to about $20 \%$. This is particularly true in the morning hours, where lower HR values are observed with respect to the afternoon hours. From an overall daily perspective, the differences between the morning/afternoon heating rates are more limited, and remain not greater than $15 \%$ in the layers with significant warming.

In this second case it is possible to conclude that the use of the simplified description of the aerosol optical properties leads to slightly higher discrepancies in the simulated DRE and heating rates. By the way, this does not alter significantly the magnitude of the aerosol direct radiative effect in the atmosphere.

\subsection{Radiative closure at the surface}

Figure 10 shows the comparison between the hourly average RTM simulations of the surface irradiance and the corresponding observations from the co-located pyranometers, for case study A. The three components of the downward irradiance (global, direct, and diffuse) are represented. The left panel shows the actual irradiances measured and simulated on March $25^{\text {th }}, 2018$, while the right panel shows the irradiances simulated and measured in clean conditions (March $23^{\text {rd }}$ ). The agreement between observations and simulations is within the expected uncertainty, in both turbid and clean conditions: the RTM simulations are able to reproduce well the surface irradiance measured by pyranometers.

The good agreement between simulated and measured irradiances is confirmed in Fig. 11, where their relative differences are compared with the relative uncertainty on pyranometer data for turbid (left) and clean (right) conditions. A slight underestimation of the simulated diffuse irradiance is found in clean conditions, although absolute differences are very low. This may be due to the fact that simulated irradiances in clean conditions are obtained with an exactly null aerosol load, while the reference pyranometer data are obtained with a very low AOD $(\sim 0.03$ at $500 \mathrm{~nm})$. 
$25 / 03 / 2018$

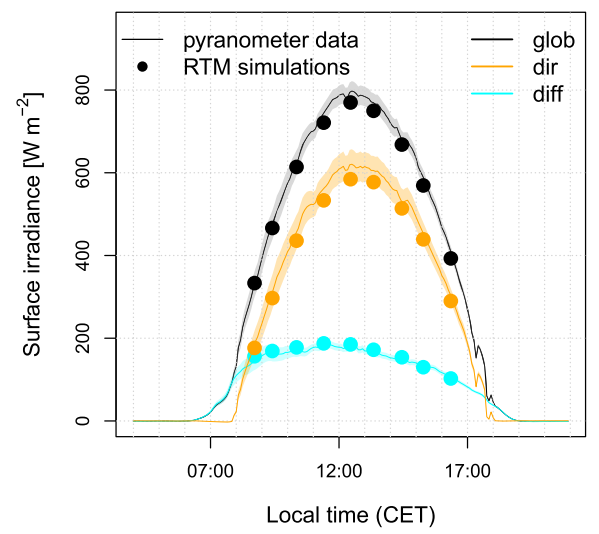

23/03/2018

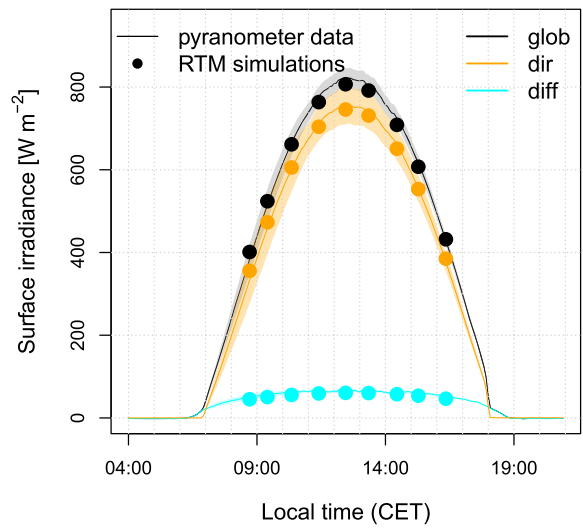

Fig. 10 Comparison between simulated and measured surface irradiances in turbid (left) and clean (right) conditions. The simulations in clean conditions are performed with a null AOD

The use of the approximate aerosol description does not affect the good agreement between simulated and observed surface irradiances: the differences in the simulated surface irradiances are very often lower than $1 \%$ and never greater than $2 \%$ between the two methods.

\subsection{Discussion}

One of the most crucial quantities in influencing the aerosol direct radiative effect and its ability to warm the atmosphere is the aerosol SSA, which determines whether the particles are more able to scatter or absorb solar radiation. The accuracy of the SSA is thus fundamental to provide a reliable estimate of the aerosol radiative effects. Since the retrieval of

$25 / 03 / 2018$

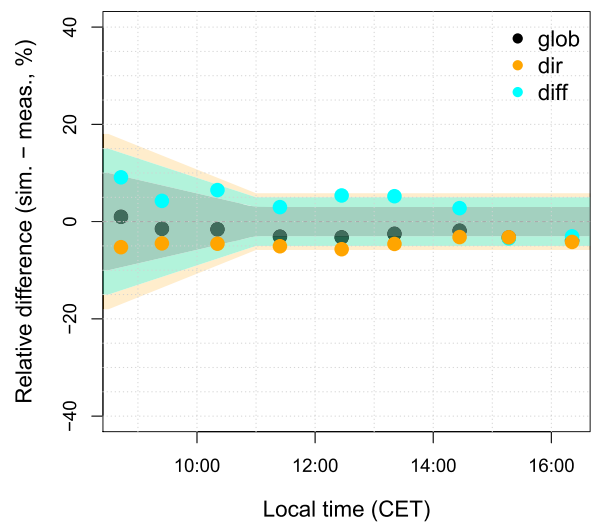

$23 / 03 / 2018$

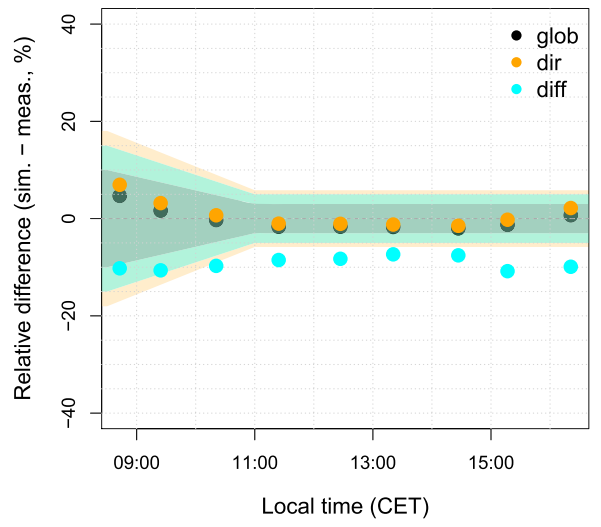

Fig. 11 Relative differences between simulated and observed surface irradiances in turbid (left) and clean (right) conditions. The uncertainty on pyranometer data is also shown. The simulations in clean conditions are performed with a null AOD 
the aerosol columnar properties also depends on the environmental quantities provided as input to Skyrad MRIv2 (listed in Table 1), inaccurate assumptions about these quantities could lead to inaccuracies in SSA. A sensitivity analysis was performed, retrieving SSA using different values for those quantities: surface albedo turned out to potentially affect the retrieved SSA, while the other quantities had minor impacts. This is particularly important for the site investigated in this study, because of the possible presence of snow cover on the mountains around the station (as in case study A). The use of a fixed surface albedo (as is currently done in the EuroSkyRad network), instead of a climatological value, could lead to large biases in the retrieved aerosol SSA. It has been found that a 0.1 shift in the surface albedo in the visible region (which is not unlikely if a fixed value is used throughout the year and snow is present on the ground) could lead to absolute differences in SSA as large as 0.07 . This can have a remarkable impact on the estimated aerosol direct radiative effect, introducing absolute changes in the DRE as large as $20 \mathrm{~W} \mathrm{~m}^{-2}$ at TOA and within the atmospheric layer, and deviations in the instantaneous heating rates up to $0.4 \mathrm{~K} \mathrm{day}^{-1}$. It should be noted, as a comparison, that the use of the approximate description of the aerosol properties in the RTM, instead of the accurate one, leads to absolute differences in SSA that are lower than 0.03 at all wavelengths, sensibly lower than the ones potentially induced by inaccurate surface albedo.

The other remarkable difference that arises from the approximate aerosol description is the use of a spectrally invariant asymmetry factor instead of the complete, wavelength dependent aerosol phase function. This issue seems to play a limited role, especially in the case of fine particles. For this kind of application, the asymmetry factor alone seems to be sufficient to give a satisfying representation of the angular distribution of the scattered radiation. Slightly higher differences, although still limited, are found in the case of coarse particles. It is possible that the angular distribution of radiation scattered by coarser particles, with a more pronounced forward peak, is represented less accurately by the asymmetry factor alone. In any case, this does not affect significantly the magnitude (nor the sign) of the aerosol direct radiative effect.

Another possible source of uncertainty is the assumption of vertical homogeneity of the aerosol, that leads to uniform SSA and phase function along the vertical coordinate. It is possible, however, that layers with different aerosol properties lay at different altitudes: for example, strongly absorbing aerosol of urban origin can be confined in the lowest atmospheric layers, while more scattering aerosol (such as secondary particles transported from the Po Valley) can be found above. In the future, other techniques and instruments (aerosol chemical analyses, optical particle counters and aethalometers operated at the surface) can be used to assess the vertical heterogeneity of the aerosol using ground-based measurements.

Using a low-power device like the ALC has the potential disadvantage of providing a low signal-to-noise ratio, and reducing the aerosol backscatter sensitivity at high altitude (such as in the free troposphere). On the other hand, this allows the instrument to be operated in unattended, continuous and eye-safe conditions, and to be less demanding in terms of costs and maintenance, with respect to more advanced research lidars (Madonna et al. 2018). In particular, employing a 1064-nm laser beam can raise possible concerns about the ALC efficiency in detecting fine mode particles, which are especially dominant in case study A. However, the reliability of the ALC in this situation can be justified by the following arguments: (a) as also stated in Section 2.3, other studies (Dionisi et al. 2018; Diémoz et al. 2019; Barragan et al. 2020; Diémoz et al. 2021) have successfully employed such an instrument in similar contexts, showing good agreement with independent data sources; 
(b) even though the backscatter from fine particles at the operating wavelength is sensibly lower (about an order of magnitude) than the backscatter from coarse mode particles, the higher number concentration of fine particles causes a rather strong signal back to the instrument; this has been checked by the calculation of daily average backscatter profiles, which show comparable magnitudes in the two case studies (both with maximums of about $7 \times 10^{-7} \mathrm{~m}^{-1} \mathrm{sr}^{-1}$ ); (c) the ability of the instrument to correctly describe the amount and daily modulation of the aerosol load has been checked in the specific situation of case study A. The column-integrated extinction coefficient from the ALC has been compared (Fig. 12) to the AOD by the co-located POM-02 sky radiometer, extrapolated at $1064 \mathrm{~nm}$ with the BBR software (Section 2.5). The comparison shows a good agreement between the two instruments, both in magnitude and in the daily trend.

The atmospheric warming quantified in this study has the potential of altering substantially the atmospheric lapse rate, influencing atmospheric stability. The particular effect on atmospheric stability crucially depends on where the warming is located, which is determined by the aerosol profile, as also found in $\mathrm{Su}$ et al. (2020). A strong heating in mid-troposphere layers, for example, can stabilise the atmosphere, thus impacting on PBL dynamics and low-level mixing.

The aerosol direct radiative effect addressed in this study only considers the interactions between aerosols and radiation in the shortwave (solar) range. Further studies are needed to assess the impact of aerosol in the longwave region (e.g. the effect of aerosol dimming on surface heating and the consequent infrared emission). Furthermore, the potential influence on atmospheric stability, and the ability of aerosol particles to act as Cloud Condensation Nuclei, could impact on the development of clouds, which interact with both shortwave and longwave radiation. Dedicated studies are needed to consider the role of clouds and their interaction with the aerosol radiative effect.

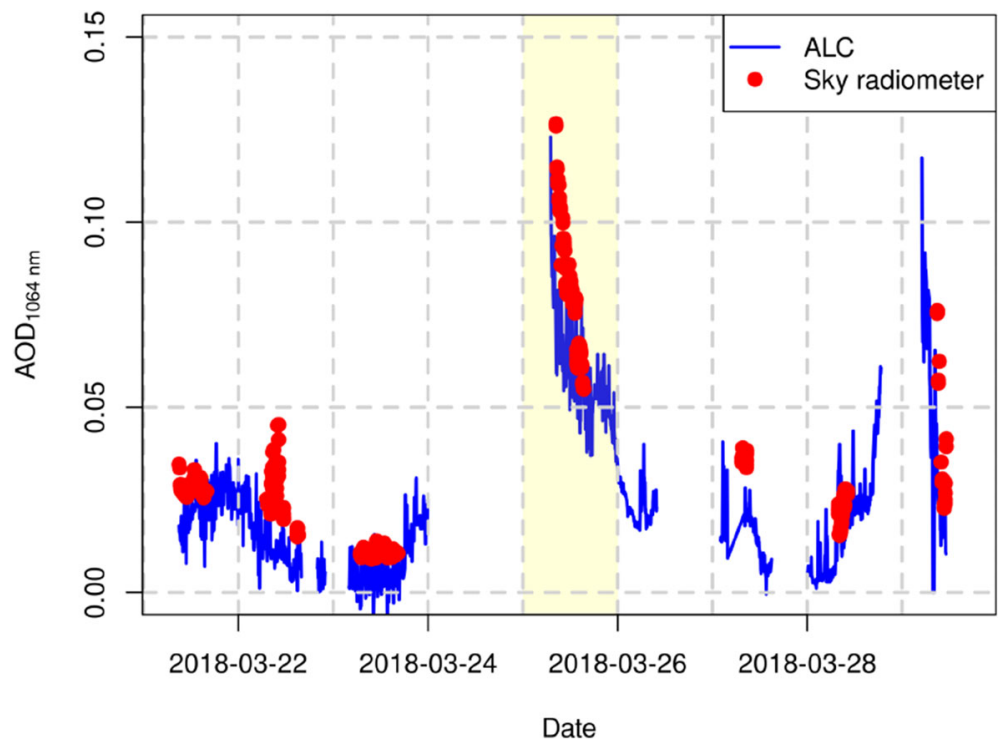

Fig. 12 comparison between the AOD obtained from the ALC and the POM-02 sky radiometer, in the period from March $21^{\text {th }}$ to $29^{\text {th }}, 2018$. Case study A (March $25^{\text {th }}, 2018$ ) is shaded in yellow. Missing data in the ALC series are due to clouds, while the sky radiometer is operative only in daytime, cloudless conditions 
Finally, it must be considered that the analysis relies on two case studies: although providing a limited dataset, the two days represent interesting and quite frequent conditions over the experimental site; moreover, the aerosol optical properties retrieved in these case studies are typical of such kind of events, as demonstrated in more extensive studies (Diémoz et al. 2014; Diémoz et al. 2019). Therefore, this work could provide a plausible indication of the aerosol direct radiative effect in such conditions, and could serve as a meaningful test for the methodology applied.

\section{Summary and conclusions}

The vertical profile of the radiative effect due to the interaction between solar radiation and aerosol (shortwave aerosol direct radiative effect) was studied over the Aosta-SaintChristophe site, at the bottom of a mountain valley in the Northwestern Italian Alps. Two case studies, with cloudless conditions and different types of aerosol were analysed: an advection of secondary aerosol from the polluted Po Valley and an event of Saharan dust transport from Northern Africa. Although providing a limited dataset, the two days are representative of interesting and quite frequent conditions over the experimental site. The aerosol optical properties were retrieved using the photometric technique, by means of a PREDE POM-02 sky radiometer and the Skyrad MRI Version 2 inversion algorithm. The aerosol vertical distribution was estimated from the observations of an Automated Lidar Ceilometer. The libRadtran radiative transfer model was used to simulate shortwave irradiances at different altitudes, and allowed to calculate the aerosol direct radiative effect (DRE) and heating rates due to aerosol absorption in the lower tropospheric layers.

The presence of the aerosol layers led to a small negative daily average DRE at the top of the atmosphere (respectively -3.4 and $-9.7 \mathrm{~W} \mathrm{~m}^{-2}$ for cases $\mathrm{A}$ and B), i.e. a small cooling for the overall Earth-atmosphere system, but with differences among the different hours of the day. The aerosol induced an evident dimming effect at the surface (respectively -33.5 and $-38.4 \mathrm{~W} \mathrm{~m}^{-2}$ for the daily average of cases $\mathrm{A}$ and $\mathrm{B}$ ). This resulted in a net flux absorption inside the atmospheric column (respectively +30.1 and $+28.7 \mathrm{~W} \mathrm{~m}^{-2}$ for cases A and B). The flux absorption led to substantial warming in the lower atmospheric layers where aerosol was found: the vertically resolved heating rates reached values up to 1.2 and $0.7 \mathrm{~K} \mathrm{day}^{-1}$ for the daily average simulations in cases $\mathrm{A}$ and $\mathrm{B}$ respectively. These results are comparable with those obtained by other studies in similar contexts. It is worth noting that the warming profile exhibited a vertical shift with respect to the aerosol extinction profile, namely being more extended upwards. This effect could be of potential interest for the topic of the Elevation-Dependent Warming. Moreover, the magnitude of the instantaneous warming is considerable, and could affect atmospheric stability and thus pollutant dispersion in the PBL. However, for a complete comprehension, the effect on longwave fluxes near the surface and effects on clouds should be also taken into account.

The use of an approximate method to describe the aerosol optical properties, which does not consider the spectral variability of the single scattering albedo and the whole phase function at the different wavelengths, but assumes constant spectral value of SSA and asymmetry factor, turned out to play a minor role in the correct representation of aerosol direct radiative effect in the cases studied.

The reliability of the radiative transfer simulations at the surface was verified for case study A by the comparison with ground-based pyranometer observations, in terms of surface irradiances. 
This study was the first attempt to quantify the aerosol direct radiative effect in the mountainous, orographically complex Aosta Valley. The obtained results showed that, in some conditions, this effect may be considerable, even in an environment usually considered as pristine. The instruments and methodologies adopted proved to be appropriate and capable of capturing the crucial information about the aerosol features and impacts. In the future, further investigation could be done to understand in more depth these phenomena, applying the methods used in this study to a wider range of conditions and to a longer dataset.

Acknowledgements We would like to acknowledge Fondazione CRT for funding the project SOUVENIR, which has allowed to financially support the research activity of Gabriele Fasano. We thank the European Cooperation in Science and Technology (COST) action "PROBE" (CA18235), which led to advancement in the use of Automated Lidar Ceilometers. We acknowledge the GEMMA center in the framework of Project MIUR - Dipartimenti di Eccellenza 2018-2022, for the contribution of Luca Ferrero.

Funding Open access funding provided by Università degli Studi di Roma La Sapienza within the CRUICARE Agreement.

\section{Declarations}

Conflict of interest The authors declare no competing interests.

Open Access This article is licensed under a Creative Commons Attribution 4.0 International License, which permits use, sharing, adaptation, distribution and reproduction in any medium or format, as long as you give appropriate credit to the original author(s) and the source, provide a link to the Creative Commons licence, and indicate if changes were made. The images or other third party material in this article are included in the article's Creative Commons licence, unless indicated otherwise in a credit line to the material. If material is not included in the article's Creative Commons licence and your intended use is not permitted by statutory regulation or exceeds the permitted use, you will need to obtain permission directly from the copyright holder. To view a copy of this licence, visit http://creativecommons.org/licenses/by/4.0/.

\section{References}

Anderson G., Clough S., Kneizys F., Chetwynd J., Shettle E. (1986) Tech. Rep AFGL-TR-86-0110

Barbaro E., de Arellano J. V., Ouwersloot H. G., Schröter J. S., Donovan D. P., Krol M. C. (2014) J. Geophys Res. Atmos. 119:5845. https://doi.org/10.1002/2013JD021237

Barragan R., Molero F., Granados-Muñoz M. J., Salvador P., Pujadas M., Artíñano B. (2020) Remote Sens. 12. https://doi.org/10.3390/rs12223699

Boucher O., Randall D., Artaxo P., Bretherton C., Feingold G., Forster P., Kerminen V. M., Kondo Y., Liao H., Lohmann U., Rasch P., Satheesh S., Sherwood S., Stevens B., Zhang X. (2013) Clouds and Aerosols. Cambridge University Press, Cambridge

Campanelli M., Nakajima T., Olivieri B. (2004) Appl. Optics 43:651. https://doi.org/10.1364/AO.43.000651

Campanelli M., Estellés V., Tomasi C., Nakajima T., Malvestuto V., Martínez-Lozano J. (2007) Appl. Optics 46:2688. https://doi.org/10.1364/AO.46.002688

Dahlback A., Stamnes K. (1991) Planet. Space Sci. 39:671. https://doi.org/10.1016/0032-0633(91)90061-E

Diémoz H., Egli L., Gröbner J., Siani A. M., Diotri F. (2013) AIP Conference Proceedings 1531:856. https://doi.org/10.1063/1.4804905

Diémoz H., Campanelli M., Estellés V., Meteorol J. (2014) Soc. Jpn 92A:1. https://doi.org/10.2151/jmsj. 2014-A01

Diémoz H., Barnaba F., Magri T., Pession G., Dionisi D., Pittavino S., Tombolato I. K. F., Campanelli M., Della Ceca L. S., Hervo M., Di Liberto L., Ferrero L., Gobbi G. P. (2019) Atmos. Chem. Phys. 19:3065. https://doi.org/10.5194/acp-19-3065-2019

Diémoz H., Gobbi G. P., Magri T., Pession G., Pittavino S., Tombolato I. K. F., Campanelli M., Barnaba F. (2019) Atmos. Chem. Phys. 19(15):10129. https://doi.org/10.5194/acp-19-10129-2019 
Diémoz H., Magri T., Pession G., Tarricone C., Tombolato I. K. F., Fasano G., Zublena M. (2021) Atmosphere 12. https://doi.org/10.3390/atmos12081006

Dionisi D., Barnaba F., Diémoz H., Di Liberto L., Gobbi G. P. (2018) Atmos. Meas. Tech. 11(11):6013. https://doi.org/10.5194/amt-11-6013-2018

Dubovik O., King M. D., Geophys J. (2000) Res. Atmos. 105:20673. https://doi.org/10.1029/2000JD900282

Dubovik O., Smirnov A., Holben B. N., King M. D., Kaufman Y. J., Eck T. F., Slutsker I., Geophys J. (2000) Res. Atmos. 105:9791. https://doi.org/10.1029/2000JD900040

Dubovik O., Holben B., Eck T. F., Smirnov A., Kaufman Y. J., King M. D., Tanré D., Slutsker I. (2002) J. Atmos. Sci. 59:590. https://doi.org/10.1175/1520-0469(2002)059/0590:VOAAOP $\rangle$ 2.0.CO;2

Dutton E. G., Michalsky J. J., Stoffel T., Forgan B. W., Hickey J., Nelson D. W., Alberta T. L., Reda I. (2001) Measurement of Broadband Diffuse Solar Irradiance Using Current Commercial Instrumentation with a Correction for Thermal Offset Errors. J. Atmos. Ocean. Tech. 18:297. https://doi.org/10.1175/1520-0426(2001)018\%3C0297:MOBDSI\%3E2.0.CO;2

Emde C., Buras-Schnell R., Kylling A., Mayer B., Gasteiger J., Hamann U., Kylling J., Richter B., Pause C., Dowling T., Bugliaro L. (2016) Geosci. Model Dev. 9:1647. https://doi.org/10.5194/gmd-9-1647-2016

Estellés V., Campanelli M., Utrillas M. P., Expósito F., Martínez-Lozano J. A. (2012) Atmos. Meas. Tech. 5:569. https://doi.org/10.5194/amt-5-569-2012

Federico S., Torcasio R. C., Sanò P., Casella D., Campanelli M., Meirink J. F., Wang P., Vergari S., Diémoz H., Dietrich S. (2017) Atmos. Meas. Tech. 10:2337. https://doi.org/10.5194/amt-10-2337-2017

Feister U., Grewe R. (1995) Photochem. Photobiol. 62:736. https://doi.org/10.1111/j.1751-1097.1995.t b08723.x

Fernald F. G. (1984) Appl. Optics 23:652. https://doi.org/10.1364/AO.23.000652

Ferrero L., Castelli M., Ferrini B., Moscatelli M., Perrone M., Sangiorgi G., D’ Angelo L., Rovelli G., Moroni B., Scardazza F., Močnik G., Bolzacchini E., Petitta M., Cappelletti D. (2014) Atmos. Chem. Phys. 14:9641. https://doi.org/10.5194/acp-14-9641-2014

Ferrero L., Močnik G., Cogliati S., Gregorič A., Colombo R., Bolzacchini E. (2018) Environ. Sci. Technol. 52:3546. https://doi.org/10.1021/acs.est.7b04320

Fuzzi S., Gilardoni S., Kokhanovsky A. A., Di Nicolantonio W., Mukai S., Sano I., Nakata M., Tomasi C., Lanconelli C. (2017) Aerosol and Air Quality, 1st edn. Wiley-VCH, Weinheim

Haeffelin M., Kato S., Smith A. M., Rutledge C. K., Charlock T. P., Mahan J. R. (2001) Appl. Optics 40(4):472. https://doi.org/10.1364/AO.40.000472

Kato S., Ackerman T. P., Mather J. H., Clothiaux E. E. (1999) J. Quant. Spectrosc. Ra. 62:109. https://doi.org/10.1016/S0022-4073(98)00075-2

Kazadzis S., Kouremeti N., Diémoz H., Gröbner J., Forgan B. W., Campanelli M., Estellés V., Lantz K., Michalsky J., Carlund T., Cuevas E., Toledano C., Becker R., Nyeki S., Kosmopoulos P. G., Tatsiankou V., Vuilleumier L., Denn F. M., Ohkawara N., Ijima O., Goloub P., Raptis P. I., Milner M., Behrens K., Barreto A., Martucci G., Hall E., Wendell J., Fabbri B. E., Wehrli C. (2018) Atmos. Chem. Phys. 18:3185. https://doi.org/10.5194/acp-18-3185-2018

Kedia S., Ramachandran S., Kumar A., Sarin M. M., Geophys J. (2010) Res. Atmos 115(D7). https://doi.org/10.1029/2009JD013136

Klett J. D. (1985) Appl. Optics 24:1638. https://doi.org/10.1364/AO.24.001638

Kudo R., Aoyagi T., Nishizawa T. (2018) Atmos. Meas. Tech. 11:3031. https://doi.org/10.5194/amt-113031-2018

Kudo R., Diémoz H., Estellés V., Campanelli M., Momoi M., Marenco F., Ryder C. L., Ijima O., Uchiyama A., Nakashima K., Yamazaki A., Nagasawa R., Ohkawara N., Ishida H. (2021) Atmos. Meas. Tech., pp. 1-32. https://doi.org/10.5194/amt-14-1-2021

LSI-LASTEM (2012) DPA245 Shadowband - User's manual

Madonna F., Rosoldi M., Lolli S., Amato F., Vande Hey J., Dhillon R., Zheng Y., Brettle M., Pappalardo G. (2018) Atmos. Meas. Tech. 11:2459. https://doi.org/10.5194/amt-11-2459-2018

Meloni D., Junkermann W., di Sarra A., Cacciani M., De Silvestri L., Di Iorio T., Estellés V., Gómez-Amo J. L., Pace G., Sferlazzo D. M., Geophys J. (2015) Res. Atmos. 120:3386. https://doi.org/10.1002/2014JD022312

Nakajima T., Campanelli M., Che H., Estellés V., Irie H., Kim S. W., Kim J., Liu D., Nishizawa T., Pandithurai G., Soni V. K., Thana B., Tugjsurn N. U., Aoki K., Go S., Hashimoto M., Higurashi A., Kazadzis S., Khatri P., Kouremeti N., Kudo R., Marenco F., Momoi M., Ningombam S. S., Ryder C. L., Uchiyama A., Yamazaki A. (2020) Atmos. Meas. Tech. 13:4195. https://doi.org/10.5194/amt-13-4195-2020

Pepin N., Bradley R. S., Diaz H. F., Baraer M., Caceres E. B., Forsythe N., Fowler H., Greenwood G., Hashmi M. Z., Liu X. D., Miller J. R., Ning L., Ohmura A., Palazzi E., Rangwala I., Schöner W., Severskiy I., Shahgedanova M., Wang M. B., Williamson S. N., Yang D. Q. (2015) Nat. Clim. Change (5) 424. https://doi.org/10.1038/nclimate2563 
Roberts D. A., Ustin S. L., Ogunjemiyo S., Greenberg J., Dobrowski S. Z., Chen J., Hinckley T. M. (2004) Ecosystems 7:545. https://doi.org/10.1007/s10021-004-0144-5

Sinyuk A., Holben B. N., Eck T. F., Giles D. M., Slutsker I., Korkin S., Schafer J. S., Smirnov A., Sorokin M., Lyapustin A. (2020) Atmos. Meas. Tech. 13:3375. https://doi.org/10.5194/amt-13-3375-2020

Srivastava A., Singh S., Tiwari S., Bisht D. (2012) Contribution of anthropogenic aerosols in direct radiative forcing and atmospheric heating rate over Delhi in the Indo-Gangetic Basin. Environ. Sci. Pollut. R 19:1144. https://doi.org/10.1007/s11356-011-0633-y

Su T., Li Z., Li C., Li J., Han W., Shen C., Tan W., Wei J., Guo J. (2020) Atmos. Chem. Phys. 20:3713. https://doi.org/10.5194/acp-20-3713-2020

Subba T., Gogoi M. M., Pathak B., Bhuyan P. K., Babu S. S. (2020) Atmos. Sci. Lett. e975:21. https://doi.org/10.1002/asl.975

Tao J. C., Zhao C. S., Ma N., Liu P. F. (2014) Atmos. Chem. Phys. 14(22):12055. https://doi.org/10.5194/ acp-14-12055-2014

Thornton J. M., Palazzi E., Pepin N. C., Cristofanelli P., Essery R., Kotlarski S., Giuliani G., Guigoz Y., Kulonen A., Pritchard D., Li X., Fowler H. J., Randin C. F., Shahgedanova M., Steinbacher M., Zebisch M., Adler C. (2021) One Earth 4(6):805. https://doi.org/10.1016/j.oneear.2021.05.005

Wiegner M., Geiß A. (2012) Atmos. Meas. Tech. 5(8):1953. https://doi.org/10.5194/amt-5-1953-2012

Publisher's Note Springer Nature remains neutral with regard to jurisdictional claims in published maps and institutional affiliations.

\section{Affiliations}

\section{Gabriele Fasano ${ }^{1,2}$ (1) $\cdot$ Henri Diémoz ${ }^{2} \cdot$ Ilias Fountoulakis $^{2} \cdot$ Claudio Cassardo $^{3}$. Rei Kudo $^{4}$. Anna Maria Siani ${ }^{1} \cdot$ Luca Ferrero $^{5}$}

1 Physics Department, Sapienza University of Rome, Rome, Italy

2 ARPA Valle d'Aosta, Saint-Christophe, Italy

3 Physics Department, University of Turin, Turin, Italy

4 Meteorological Research Institute, Japan Meteorological Agency, Tsukuba, Japan

5 GEMMA and POLARIS Centre, University of Milano-Bicocca, 20126, Milan, Italy 